\title{
Women Asylum Seekers and Refugees: Opportunities, Constraints and the Role of Agency
}

\author{
Lisa Hunt \\ Salford Housing and Urban Studies Unit (SHUSU), School of Environment and Life Sciences, \\ University of Salford \\ E-mail: I.hunt@salford.ac.uk
}

This article is based on the findings of research undertaken towards a doctoral thesis funded by the University of Leeds. The research focuses upon the actions and experiences of women asylum seekers and refugees living in West Yorkshire. While acknowledging that the context in which women find themselves can present a number of barriers, this paper looks at their actions and practices at the individual and collective levels. It illustrates that some women are able to draw on the resources available, and are engaged in activities that not only assist their own settlement in the host society but also assist the development of support structures for future arrivals of asylum seekers and refugees.

\section{Introduction}

Since the 1990s the issue of asylum has become a major concern, not just in the United Kingdom (UK), but across the whole of Western Europe. Successive governments have introduced a host of measures aimed at restricting the number of people allowed entry to the UK. For those who make it past the border, rights to employment have been curtailed, entitlement to financial support has been restricted and accommodation offered on a 'no choice' basis. Politicians and the media have questioned people's reasons for coming to the UK, and, instead of looking at the increase in conflict around the globe, argue that many are 'economic migrants' abusing the welfare system, using the asylum route to gain access for employment, or, more recently, posing a threat to national security. In some respects, asylum seekers have come to represent a new 'moral panic' (Cohen, 2002).

Against this backcloth of media disdain and restrictive policy, a growing body of literature has focused upon the experiences of refugees and people seeking asylum at international, European, national and local levels. This paper seeks to add to this knowledge, with a particular commitment to providing perspectives from women asylum seekers and refugees, whose experiences have sometimes been overlooked, or whose role has been regarded as 'secondary' or 'dependent' (Bloch et al., 2000).

Underpinning this paper is a focus upon the interplay between structure and agency. Here, structure refers to the environment of opportunities and constraints in which we find ourselves and which influence our actions, while agency refers to people's capacity to act (Williams and Popay, 1999), either individually or collectively.

This particular study focuses on the women as creative agents, drawing upon resources and creating opportunities to improve their lives in the exile setting. We must consider, however, that the concept of agency can sometimes be based on limited ideas of 'socially valuable contribution', which undervalues the actions of those who are not 
permitted to enter the labour market (Dwyer, 2004). This indeed applies to the situation of asylum seekers and the restrictions placed on them in terms of access to employment. It is therefore vital to look at the importance of both paid and voluntary work, as well as social practices, such as building up support networks.

The relationship between structure and agency has been the subject of much debate (Giddens, 1984; Williams et al., 1999; Lister, 2004). This paper draws specifically on the work of Archer (1995), who looks at the interplay between the two in terms of a 'morphogenetic cycle' with three phases:

1 Agents encounter structural conditions

2 Within these conditions, people pursue their interests

3 These actions result in the elaboration or modification of the original structural conditions

In Archer's work, there is a pre-existence of structures, or a 'structural inheritance', which leaves people involuntarily situated. Within this inherited situation, the interaction between individuals and their environment results in the transformation of the original conditions. Thus, this paper looks at the practical constraints and opportunities that women asylum seekers and refugees face in the host society, in terms of access to basic rights, services and resources. At the same time, it focuses on their actions and strategies in the exile setting. Ultimately, this paper will show that people seek out opportunities as 'creative' agents and that their actions can change the context for future arrivals.

\section{Women in exile: lessons from previous studies}

Women have been travelling the globe for centuries (see Wright, 1995, for example, who offers an account of African women's migration), as part of nomadic groups, exiles and migrant workers. In terms of women asylum seekers and refugees specifically, it is suggested that there has been a bias towards male refugees (Kay, 1989), or a 'gender neutrality', which can neglect or hide the specific problems or resources of refugee women (Camus-Jacques, 1989). Where studies have focused on women as forced migrants, they have often looked at their experiences of persecution (see Refugee Women's Legal Group, 1998; Crawley, 2001), or their unequal access to the asylum determination process (see Crawley, 2001; Refugee Women's Resource Project, 2003). There have also been a number of studies focusing on specific aspects of the exile experience; for example, pregnancy (Maternity Alliance, 2002a, 2002b), employment (Sargeant et al., 1999; Dumper, 2002), and, more recently, the need for a 'woman-centred' asylum support system (Refugee Council, 2005).

This is not to suggest that there is no research focusing on the importance of women's strategies and actions. Indeed, there are a number of studies that counterbalance the view of women as 'secondary'. Berghahn (1995), for example, looks at the significance of Jewish women fleeing Nazi Germany. In many cases, these women were from middleclass backgrounds, but often had to take on paid domestic roles to support their families. Berghahn argues that women were more able to adapt to a 'loss of status' than men:

On the whole women were more flexible and ready to grasp whatever opportunity offered itself to boost the meagre family income. It mattered less to them that most jobs were badly paid and in many cases illegal. (1995: 76) 
Similarly, with reference to Bosnian refugees, research by Franz (2003) highlights that many Bosnian men were also unable to adapt to the loss of social status. Like the women in Berghahn study, many Bosnian women were concerned about their families' futures and how to advance their situation in the new society:

Women were relatively non-selective and willing to take any job ... [they] behaved more 'pragmatically' than Bosnian men during the time of adaptation in the host society. (Franz, 2003: 92)

Ui (1991) illustrates a similarly pragmatic approach in a study of Cambodian refugee women in Stockton, California. One of the 'strategies of survival' was to use their 'traditional roles' of providing food and making clothes as a means of generating income for the family. For Ui, the interplay between structure and agency was important as this focused not only on the women as active agents, but also on the institutional arrangements in Stockton that offered opportunities for the women. Programmes designed specifically to support the Cambodian refugees, for instance, led to the creation of jobs in the social services; positions that were primarily filled by women. Thus:

Whether they work in the informal economy of the Cambodian community or in social service jobs in the paid labour force, women become the primary breadwinners in Cambodian families.

(Ui, 1991: 171)

\section{Methods and background}

The research was carried out between 2002 and 2005 and involved 42 semi-structured in-depth interviews; 21 interviews were carried out with women asylum seekers and refugees and 21 with key informants from statutory and voluntary organisations across Bradford, Halifax, Huddersfield, Leeds and Wakefield. In addition, a number of informal meetings with representatives from selected agencies took place, as well as observation at two asylum seeker support groups for women. Key informants were employed in a range of organisations, including local authority asylum teams, voluntary organisations and refugee community organisations (RCOs).

The women asylum seekers and refugees who took part in the study came from Albania, Angola, Burundi, Iran, Iraq, Kosovo, Lebanon, Liberia, Pakistan, Sudan and Zimbabwe. They were aged between 18 and 55, with the majority of respondents falling in the range of 26-45 years of age. The list of previous occupations/professions of the women included dentist, factory worker, hairdresser, 'homemaker', nurse, midwife, student, tailor, teacher and working in telecommunications.

In terms of legal status, 11 of the women were asylum seekers, at various stages of their application, ranging from initial interview to final appeal; seven women had refugee status; two women were in the UK under family reunification rules through their husbands' application; and one woman had Exceptional Leave to Remain (ELR). ${ }^{1}$ Seventeen of the women had dependent children, either with them or waiting to join them in the UK. The length of time the women had been in the UK varied from six months to ten years, illustrating the diversity of experiences, but also providing comparisons between relatively new arrivals and those who were more established. 
The use of 'snowball' sampling is often regarded as one of the best methods of accessing vulnerable or hidden populations in the absence of an appropriate sampling frame and is potentially one of the only effective methods of gaining access to asylum seekers and refugees (Bloch, 1999a). A further consideration was that, at the time of the research there was a degree of 'research fatigue' in some areas (and indeed in some organisations), as a number of students and other agencies, were carrying out research with refugees and asylum seekers in West Yorkshire (see Robinson, 2002 for a discussion on research fatigue). Consequently, there was a need for a pragmatic approach with regard to identifying interviewees as it was not always possible to make fully 'pre-planned' choices. The aim, however, was to cover a range of countries of origin and circumstances, in order to reflect the diversity of the population of asylum seekers and refugees in the region. The use of 'gatekeepers', from various agencies, was essential and through them initial introductions to potential interviewees were made.

All of the interviews were conducted at locations suitable to the respondent. For the women asylum seekers and refugees, these were carried out in their own homes, unless they specified another location. This approach enabled the women to retain some sense of control over the situation, particularly when talking about potentially 'sensitive topics' (Bergen, 1993). In most cases, people were forthcoming about their experiences in their countries of origin, which could be explained, in part, by the researcher being female. However, there are factors, other than the gender of the researcher, which may be more important. One voluntary worker from a women's support group, for example, highlighted that people often want you to 'bear witness' to their experiences and that this process can be 'cathartic'. Furthermore, asylum seekers, to some extent are used to telling their 'stories' because of what is expected in asylum interviews.

Another consideration was the issue of language, as the sample included women whose command of English was not very proficient. Some interviews therefore required the assistance of an interpreter. ${ }^{2}$ The women were given a choice of professional interpreters or 'informal' interpreters and the favoured approach was to use an interpreter (where applicable) who was suggested by the women themselves. In three cases, these interpreters were in fact male, but were chosen because they had helped in other situations; for example, in interactions with service providers. The implications of using interpreters have been discussed elsewhere (see for example Edwards, 1998; Temple and Edwards, 2002). It is, therefore, not the purpose of this paper to revisit these issues, but rather acknowledge that the use of interpreters is not unproblematic and that an element of pragmatism was employed. In order to ensure anonymity, the women were asked to choose alternative names for themselves.

\section{The structural context}

\section{Dispersal to West Yorkshire}

Previous research in the region has highlighted positive responses by many local organisations following the implementation of dispersal (Wilson, 2001). ${ }^{3}$ It was clear that there were key statutory and voluntary organisations in West Yorkshire, whose remit was the provision of support for asylum seekers and refugees. Prior to dispersal, many areas of West 
Yorkshire were already diverse in terms of existing multicultural populations, particularly Bradford, Huddersfield and Leeds. Furthermore, some authorities had previous experience of supporting asylum seekers due to their involvement in the reception of Kosovan refugees from the evacuation programme in 1999. However, as would be expected, the level of support varied between different authorities and there were some areas with little or no previous experience of providing the support necessary for such populations. What was apparent was that in these areas, rather than key organisations, there were key individuals within existing agencies, who would take on this role.

\section{'Loss of status'}

One of the most difficult aspects of the exile experience for the women was the 'loss of status' associated with being an 'asylum seeker' or 'refugee'. This classification not only had negative associations, particularly in terms of public perception, but also placed constraints on their ability to move forward with their lives in exile:

it's like you're not in control of your life. . .I remember when I handed over my passport, I cried, you know, it's like I asked myself 'who am I now?'. It's like you are nobody, that identity is gone and you are just a refugee, you are just a figure ... it's the hardest time because you don't know what to do, you don't know whether you're going to get refugee status or not, you can't decide, you can't plan. (Margaret, Sudanese woman)

In many interviews, people compared their current status with their previous occupations or professions, illustrating their desire to be identified in terms of these occupations:

I am a qualified midwife. I have a degree from Iran ... I worked in Iran and then I was happy because I had a good job, good family, good house, everything. (Maryam, Iranian woman)

I've worked in my country for telecommunications company for 22 years ... I'm not used to staying just at home like housewife and watching TV, or cleaning or cooking. (Pranvera, Albanian woman)

Particularly frustrating for many of the women was the inability to work. The government's decision to remove entitlement to paid employment for those who had not yet received a positive decision was regarded as one of the biggest barriers to successful settlement and integration. The women had many skills and qualifications from their countries of origin that were effectively being wasted. Loss of status was frustrating for them, and long periods without using their skills could have knock-on effects on their mental health, at a time when they were perhaps already vulnerable. Many were used to working and earning their own money, and thus found dependence difficult to adapt to. Even for those who had permission to work, however, there were barriers preventing their satisfactory transition into the labour market; for example, language, non-recognition of qualifications, lack of references, and discrimination by employers and recruitment agencies.

Concerns about loss of status and inability to work were compounded by the low level of financial support available, and changes to the rules of entitlement. At the time of the study, Section 55 of the Nationality, Immigration and Asylum Act (2002) had led to 
an increase in homelessness and destitution amongst asylum seekers. Although Section 55 has been reviewed by government, destitution still remains an issue (Dwyer and Brown, 2005; Lewis, 2007), and when combined with restriction on the right to work, can force people to become reliant on other asylum seekers, whose own situation is not entirely favourable. Dwyer and Brown's (2005) research with forced migrants in Leeds, for example, highlights that a number of people have, at some time, had to rely upon other forced migrants for accommodation. In addition to a reliance on the charity of others, such restrictions can also push people into vulnerable and exploitative situations, as one voluntary worker highlights:

They become forced into prostitution, sex work of some description, and there are a number of women I know in that position. And that will even be by their husbands in this country because of course, that's their resource. (Voluntary worker, Women's centre)

'Inappropriate' dispersal

It emerged from the interviews that there were a number of instances of, what was regarded as, 'inappropriate' dispersal, involving a lack of consideration for health/bodily circumstances, legal status, previous situation in terms of support, and appropriateness of the area to which people were being sent. One woman, for instance, had been dispersed in the very late stages of her pregnancy and forced to endure a seven hour coach journey. Furthermore, she had been separated from relatives and friends who she was relying upon to provide a vital support network for her as a lone parent. Some of the interviews revealed that people found it difficult without their extended family networks, where there would usually be a number of women to look after the children. Indeed, it can sometimes be the case that women have to take on a greater domestic role in the UK, as they are without these networks.

More generally, people were often unhappy about the lack of self-determination with regards to where they could live:

[I am] like a prisoner because [I have] no choice ... [I] thought that when I came to free country, [l am] free to choose, but now [I have] no right to choose because I need the support. So [I] become a prisoner of the support and have to stay in a town [I] don't like. (Iran, Iranian woman)

For Iran, the lack of choice over where to live was a particular problem as her son was currently living in the South of England, but she was unable to join him. Instead, she was forced to make frequent and costly visits to see him.

The lack of self-determination was also exacerbated when a person had spent many weeks or months in another region before being dispersed to West Yorkshire. One woman, for example, described her move to West Yorkshire as a 'second migration', while others talked about having to leave friends they had made in other areas.

\section{The role of agency}

There were a number of ways that the women sought opportunities to move forward with their lives and agency was evident in different practices; for example, buying a car 
(consumption practices), attending support groups (social practices), attending college courses (education practices), and paid or voluntary work (employment practices).

With regard to employment practices specifically, the advantages of asylum seekers and refugees entering the labour market have been the focus of a number of previous studies (see for example Duke, 1996; Bloch, 1999b). It is not just asylum seekers and refugees themselves who benefit positively, but also the agencies that employ them, either in a paid or voluntary capacity. Here, the service providers talked about the language skills asylum seekers and refugees brought, as well as their 'experience' as asylum seekers, which could help 'bridge the gap' between the service providers and those who came to them for support. It was felt that employment was vital in terms of helping asylum seekers and refugees integrate into society. Indeed, it was suggested that work was one of the key ways for women to become part of the wider community, as one voluntary worker points out:

I believe gaining employment is a real crux to playing a role in society, being integrated and having a voice, to some degree, in the way in which services are developed, because you're actually playing an active part in it. (Voluntary worker, women's centre)

Eight of the women who were interviewed were undertaking either voluntary or paid work (depending on their legal status). They had a range of different roles, but all of them were doing something that was caring or supportive in nature; for example, advocacy and support work with asylum seekers and refugees, teaching, care work, and church-based voluntary work. Those who were currently working in a supportive capacity with other asylum seekers and refugees often felt that they were the 'experts', having themselves been through the system:

It's easier to talk to somebody who's been through that process ... most of my clients tend to move towards me because I've got first hand experience of going through the system. (Savannah, Sudanese woman working for a voluntary BME organisation)

I'm working here now because I've gone through all the problems, so other asylum seekers maybe will go through [the] problems that I've gone through and I will be able to help. (Pranvera, Albanian woman working for a voluntary asylum support agency)

Having gone through the same kind of experience as any other asylum seeker, whatever problems, difficulties, obstacles ... I will have a better picture of what it is all about, all the emotions involved. (Margaret, Sudanese woman working for a national refugee organisation)

For those who had not received a decision on their asylum case, undertaking voluntary work gave them the opportunity to use their skills and qualifications and helped counteract the loss of status they sometimes felt. Furthermore, there was a desire to reciprocate the help they had received when they first arrived in this country. The women did not like 'getting something for nothing' and it was important to them to feel that they had in some way contributed in the UK. Finch and Mason (1993) refer to this as 'generalised reciprocity', whereby people 'pay back' the support they have received by giving the same kind of support to a third party.

There were also more pragmatic reasons for women's involvement in voluntary work. One woman had assisted in establishing a refugee community organisation (RCO) in the 
region. As well as the desire to assist their 'members', it was clear from her account that she also hoped that her work would make a 'good impression' at a higher level, particularly in terms of potentially helping her asylum case:

And they they'll say 'these people are really trying to help themselves' ... Home Office see you are really trying to help yourself. (Beatrice, Burundian woman working for a RCO)

Looking specifically at the relationship between the women's actions and the context in which they find themselves, the account of one interviewee, Margaret, provides a clear example of the interplay between the two. Margaret was a Sudanese refugee, who had been in the UK for ten years. Her account shows her journey from unpaid voluntary work through to her current paid position at a national refugee organisation, involved in awareness-raising sessions for local practitioners around negative cultural practices such as female genital mutilation (FGM). She stated that she had been 'compelled by the environment and society in the UK to get involved'. This was referring to two things: the first was the fact that in her country of origin, male relatives had looked after her rights, while in the UK she was alone with only herself to take on the role; secondly, she had arrived in the UK at a time before there were any established agencies for asylum seekers and refugees, and long before NASS. It had taken determination and creativity to reach the position she had today and what this demonstrates is that her efforts, and the efforts of others like her, had led to improvements in the support available for asylum seekers and refugees. Indeed, a number of the women in this study were assisting in the development of support services in West Yorkshire. In effect, through their work, they were playing a role in changing the structural context for future arrivals of asylum seekers.

One common theme emerging from the women's accounts was a 'process' of transition from initial 'culture shock' to being more 'settled', particularly in terms of feeling at home in an area, being engaged locally and, in some cases, finding employment. Social practices, such as establishing a support network, were vital for this process, whether facilitated by one of the service providers, or built up informally through their own dayto-day interactions. Schools, for example, featured as a positive pathway for women, enabling them to build up support networks as they became friends with other mothers and began sharing the responsibility for taking children to school or collecting them. In some respects, this created similar types of networks to those in their country of origin, particularly with regards to the shared responsibility for child care. It also appeared to put the women in this study in a more active or integrative position than some men, who perhaps did not have such a resource to draw upon.

The women interviewed were at different stages in the 'process', and, as such, their needs differed. Some were focusing on initial 'survival', for example through access to health care, financial support and accommodation, while for other women, there was a transition to looking at developing their skills, for instance through college courses or moving into employment. One voluntary worker describes the process in relation to her experience of working with an asylum seekers support group for women:

When I think of some of the women that came to the first session ... and just how nervous they were that first time, and now, just how thriving they are. They are participating in the decision making about what the group wants to do ... it's slowly about people finding their feet isn't it, and then their needs change, because now, for some of those women it's about their personal 
development and looking at training and what they'd like to do, and what skills they can take

back. (Voluntary worker, women's support group)

When looking at the women's transition we must also consider that there are other factors that will affect the process. These can refer to their current legal status, for example, and those with secure status are often in a better position to move forward with their lives than those still awaiting a decision on their case. It can also refer to the women's background in terms of country of origin or previous education, qualifications and employment experiences. For instance, those who were active, economically and/or politically, in their own country often had a desire to remain active in exile. Again, there were women who did not fit this 'profile'; for example, those who were not used to working or taking care of themselves who were now taking on these new responsibilities:

I'm staying alone, I'm paying my bills, my electric, gas, rent, telephone bills. . .it's really changed because I've never done it before. (Samantha, Zimbabwean woman working in a care home)

What is clear is that there were a number of factors influencing the transition process and the women's actions within this process. It is therefore difficult to pinpoint specific characteristics that distinguish those who were seeking out and creating opportunities. What seems to unite them, however, was their determination to overcome negative experiences (in their country of origin and in the UK), and their pragmatism and creativity in moving forward with their lives.

\section{Conclusion}

This paper has sought to add to the knowledge about women asylum seekers and refugees by looking at the interplay between two aspects of their exile experience. The first focused upon the structural context faced by women asylum seekers living in West Yorkshire. As well as the practical barriers in terms of access to financial support or employment, one of the main concerns for people was their perceived loss of status in exile, which stemmed from their legal status. This is often exacerbated by the 'state of suspension' they face while awaiting the outcome of their asylum application (which in some cases can be a very lengthy process). What was interesting was that removal from one situation places the women in another structural context. Those who receive a positive decision on their case, for example, left the 'support' of NASS and joined the 'mainstream' system, where they faced new rules, resources and constraints.

Despite the weight of negative experiences and restrictive governmental policies, however, this paper has revealed aspects that are more positive. With regards to dispersal, there have been a number of studies that highlighted its problems (see, for example, Jones, 1983; Robinson and Hale, 1989; Robinson et al., 2003), and indeed the author's research suggested numerous flaws; however, it has also revealed evidence that there are positive effects. It had led to the development of diverse social networks, particularly as many women were housed in areas, visited organisations and attended events, where they come into contact with people from a variety of backgrounds. This included engaging with people from the UK, which, for many women was regarded as a useful 'resource' to draw upon, providing the opportunity (and sometimes the impetus) to improve and 
practice their language skills. Furthermore, the fact that the women in this study did not appear to identify themselves as 'victims' and often referred to their previous positions and occupations, illustrated their unwillingness to be categorised according to their legal status.

Focusing upon the interplay between the women, as creative agents, and the context in which they find themselves, it was clear that their actions and practices had changed the conditions (albeit in perhaps modest ways) for future arrivals. People who were dispersed to West Yorkshire were now able to draw upon the skills, experience and knowledge of these women. What results from this process is the continual development of the services and support for asylum seekers and refugees. Service providers were also, to some extent, involved in this process as well. Indeed, it has been suggested that there is a need to focus on the agency of professionals and not just the welfare user (Hunter, 2003). It appeared that many service providers had seen their roles develop since dispersal began, often taking on multiple roles, in terms of advising and supporting around issues that perhaps were not part of their original remit. Thus, although an asylum seeker may have visited service provider staff in their capacity as 'education officer' or 'employment worker', once trust was built up, the client would return to that individual for help on other matters; for example, housing, benefits or even advice about their asylum case. There were also those who were running women's centres and had developed their services to incorporate the specific needs of women asylum seekers, including having weekly meetings where legal representatives or counselling services would attend, if necessary.

For some service providers, this widening of their responsibilities was not without its problems and some were now being forced to take on a more 'policing' role, expected to report instances of illegal work, for example. The interviews with key workers illustrated that they were often caught up in the dichotomy between care and control and they voiced frustration at wanting to be able to help people as much as possible, but, at the same time, being bound by the rules laid down by central government policy.

What was clear, however, was that service providers at the grass roots were involved in developing services and encouraging the formation of support networks and RCOs in the region. They also, to some extent, 'softened' the effects of policy at a grass roots level. Above all, this paper places all agents (asylum applicants, refugees and grass roots workers) as potentially having some independent effects, despite the constraints they may face.

\section{Notes}

1 ELR was previously granted when someone did not meet the criteria of the 1951 Convention relating to the Status of Refugees, but still required protection for humanitarian reasons. It was usually granted for a period of four years. In April 2003, ELR was replaced by 'humanitarian protection', which has more strictly defined circumstances.

2 The use of interpreters was made possible by the Al Charitable Trust, who kindly provided a grant to assist this part of the fieldwork.

3 Rules introduced in the Immigration and Asylum Act (1999) made access to basic housing and social security provision conditional on asylum seekers accepting compulsory, no choice, 'dispersal' to locations across the UK as specified by the National Asylum Support Service. Subsequently, considerable numbers of asylum seekers have been 'dispersed' to towns and cities across Britain. 


\section{References}

Archer, M.S. (1995), Realist Social Theory: The Morphogenetic Approach, Cambridge: Cambridge University Press.

Bergen, R.K. (1993), 'Interviewing survivors of marital rape: doing feminist research on sensitive topics', in C.M. Renzetti and R.M. Lee (eds), Researching Sensitive Topics, London: Sage, pp. 197211.

Berghahn, M. (1995), 'Women émigrés in England', in S. Quack (ed.), Between Sorrow and Strength: Women Refugees of the Nazi Period, Cambridge: Cambridge University Press, pp. 69-80.

Bloch, A. (1999a), 'Carrying out a survey of refugees: some methodological considerations and guidelines', Journal of Refugees Studies, 12, 4, 367-83.

Bloch, A. (1999b), 'Refugees in the job market: a case of unused skills in the British economy', in A. Bloch and C. Levy (eds), Refugees, Citizenship and Social Policy in Europe, Basingstoke: Macmillan.

Bloch, A., Galvin, T. and Harrell-Bond, B. (2000), 'Refugee women in Europe: some aspects of the legal and policy dimensions', International Migration, 38, 2, 169-88.

Camus-Jacques, G. (1989), 'Refugee women: the forgotten majority', in G. Loescher and L. Monahan (eds), Refugees and International Relations, New York: Oxford University Press, pp. 141-57.

Carter, B. (2000), Realism and Racism: Concepts of Race in Sociological Theory, London: Routledge.

Cohen, S. (2002), Folk Devils and Moral Panics: The Creation of the Mods and the Rockers, London: Routledge.

Crawley, H. (2001), Refugees and Gender: Law and Process, Bristol: Jordans.

Duke, K. (1996), 'The resettlement experience of refugees in the UK: main findings from an interview study', New Community, 22, 3, 461-78.

Dumper, H. (2002), Missed opportunities: A skills audit of refugee women in London from the teaching, nursing and medical professions, London: Greater London Authority in association with the Refugee Women's Association (RWA).

Dwyer, P. (2004), 'Agency, "dependency" and welfare: beyond issues of claim and contribution', in H. Dean (ed.), The Ethics of Welfare: Human Rights, Dependency and Responsibility, Bristol: The Policy Press, pp. 135-54.

Dwyer, P. and Brown, D. (2005), 'Meeting basic needs? Forced migrants and welfare', Social Policy and Society, 4, 4, 369-80.

Edwards, R. (1998), 'A critical examination of the use of interpreters in the qualitative research process', Journal of Ethnic and Migration Studies, 24, 2, 197-208.

Finch, J. and Mason, J. (1993), Negotiating Family Responsibilities, London: Routledge.

Franz, B. (2003), 'Bosnian refugee women in (re)settlement: gender relations and social mobility', Feminist Review, 73, 86-103.

Giddens, A. (1984), The Constitution of Society: Outline of the Theory of Structuration, Cambridge: Polity Press.

Hunter, S. (2003), 'A critical analysis of approaches to the concept of social identity in social policy', Critical Social Policy, 23, 3, 322-44.

Jones, P.R. (1983), 'Vietnamese refugees in the UK: the reception programme', New Community, 5, 3, 444-53.

Kay, D. (1989), 'The politics of gender in exile: Chileans in Glasgow', in D. Joly and R. Cohen (eds), Reluctant Hosts: Europe and its Refugees, Aldershot: Avebury, pp. 104-24.

Lewis, H. (2007), Destitution in Leeds: The Experiences of People Seeking Asylum and Supporting Agencies, York: Joseph Rowntree Charitable Trust.

Lister, R. (2004), Poverty, Cambridge: Polity Press.

The Maternity Alliance (2002a), Mothers in Exile: Maternity Experiences of Asylum Seekers in England, London: The Maternity Alliance.

The Maternity Alliance (2002b), A Crying Shame: Pregnant Asylum Seekers and Their Babies in Detention, London: The Maternity Alliance. 
Refugee Council (2005), Making Women Visible - Strategies for a More Woman-Centred Asylum and Refugee Support System, London: Refugee Council.

Refugee Women's Legal Group (RWLG) (1998), Gender Guidelines for the Determination of Asylum Claims in the UK, London: RWLG.

Refugee Women's Resource Project (RWRP) (2003), Women Asylum Seekers in the UK: A Gender Perspective - Some Facts and Figures, London: RWRP Asylum Aid.

Robinson, V. (2002), 'Doing research with refugees and asylum seekers', Swansea Geographer, 37, 61-7.

Robinson, V. and Hale, S. (1989), 'The geography of Vietnamese secondary migration in the UK', Research Paper in Ethnic Relations No. 10, Centre for Research in Ethnic Relations, Coventry.

Robinson, V., Andersson, R. and Musterd, S. (2003), Spreading the 'Burden'? A Review of Policies to Disperse Asylum Seekers and Refugees, Bristol: The Policy Press.

Sergeant, G., Damachi, D. and Long, D. (1999), Turning Refugees into Employees: Research into the Barriers to Employment Perceived by Women Refugees in London, London: The Industrial Society in association with Fair Play London.

Temple, B. and Edwards, R. (2002), 'Interpreters/translators and cross-language research: Reflexivity and border crossings', International Journal of Qualitative Methods, 1, 2, Article 1, available at http://www.ualberta.ca/ ijgm/english/engframeset.html, 4 December 2006.

Ui, S. (1991), "Unlikely Heroes": the evolution of female leadership in a Cambodian ethnic enclave', in M. Buraway, A. Burton, A. Arnett Ferguson, K. J. Fox, J. Gamson, N. Gartrell, L. Hurst, C. Kurtzman, L. Salzinger, J. Schiffman and S. Ui (eds), Ethnography Unbound: Power and Resistance in the Modern Metropolis, Berkeley, CA: University of California Press, pp. 161-77.

Williams, F. and Popay, J. (1999), 'Balancing polarities: developing a new framework for welfare research', in F. Williams, J. Popay and A. Oakley (eds), Welfare Research: A Critical Review, London: UCL Press, pp. 156-83.

Williams, F., Popay, J. and Oakley, A. (eds) (1999), Welfare Research: A Critical Review, London: UCL Press.

Wilson, R. (2001), Dispersed: A Study of Services for Asylum Seekers in West Yorkshire December 1999March 2001, York: Joseph Rowntree Charitable Trust.

Wright, C. (1995), 'Gender Awareness in Migration Theory: Synthesizing Actor and Structure in Southern Africa', Development and Change, 26, 771-791. 